\title{
Study on the cross-linked molecularly imprinted poly(methacrylic acid) and poly(acrylic acid) towards selective adsorption of diuron
}

\author{
Ademar Wong ${ }^{\mathrm{a}}$, Fernanda Midori de Oliveira ${ }^{\mathrm{b}}$, \\ César Ricardo Teixeira Tarley ${ }^{\mathrm{b}, \mathrm{c}, *}$, Maria Del Pilar Taboada Sotomayor ${ }^{\mathrm{a}}$ \\ a Departamento de Química Analítica, Instituto de Química, Universidade do Estado de São Paulo (UNESP), CEP 14801-970 Araraquara, SP, Brazil

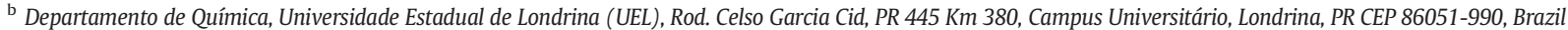

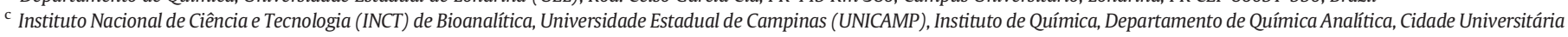 \\ Zeferino Vaz s/n, CEP 13083-970, Campinas, SP, Brazil
}

\section{A R T I C L E I N F O}

\section{Article history:}

Received 18 October 2015

Received in revised form 31 December 2015

Accepted 4 January 2016

Available online 8 January 2016

\section{Keywords:}

Isotherm

Modelating

MIP

Kinetic

\begin{abstract}
A B S T R A C T
In the present study new molecularly imprinted adsorbents based on poly(methacrylic acid) and poly(acrylic acid) have been synthesized, characterized and evaluated as selective materials for the adsorption of diuron. Morphological, textural data and the presence of functional groups in the polymer have been evaluated by means of SEM, nitrogen adsorption-desorption assays and FT-IR, respectively. Two functional monomers were evaluated for the MIP synthesis, methacrylic acid (MIP $\left.\mathrm{MAA}_{\mathrm{A}}\right)$ and acrylic acid $\left(\mathrm{MIP}_{\mathrm{AA}}\right)$, and the first one showed higher selectivity and better adsorption towards diuron in the presence of competitor molecules, carbofuran and 2,4-D. The experimental adsorption isotherm of diuron has been obtained at $\mathrm{pH} 7.0$ in phosphate buffer $\left(0.05 \mathrm{~mol} \mathrm{~L}^{-1}\right)$ :acetonitrile $(1: 2, v / v)$ medium and equilibrium time of $180 \mathrm{~min}$. The respective maximum adsorption capacities (MAC) of MIP $\mathrm{MAA}$ and $\mathrm{MIP}_{\mathrm{AA}}$ were found to be 14.58 and $7.32 \mathrm{mg} \mathrm{g}^{-1}$. One should note that MAC of MIP ${ }_{A A}$ and its respective blank polymer (NIP ${ }_{A A}$ ) was very similar to each other, while for the MIP ${ }_{\mathrm{MAA}}$ its MAC was significantly higher $\left(14.58 \mathrm{mg} \mathrm{g}^{-1}\right)$ than the MAC of NIP strates the great influence of monomer on the adsorption and selectivity of MIP. Adsorption kinetic data were well fitted to pseudo-first-order and intraparticle diffusion models, while the adsorption isotherms showed good fit to the isotherm of Langmuir-Freundlich for two sites (LF-2) and one site (LF-1), but the former one allowed insight into the adsorption mechanism with more details.
\end{abstract}

(c) 2016 Elsevier B.V. All rights reserved.

\section{Introduction}

Diuron is a herbicide, which belongs to the class of phenylurea and has been widely used to control weeds in a variety of crops, such as sugarcane, coffee, alfalfa, rice, soybean, potato and cotton $[1,2]$. Although diuron has not been considered highly hydrophilic and highly toxic to fish and aquatic organisms, it possesses high toxicity to plants and has been classified as a pesticide of great potential for human health $[3,4]$. The human exposure to diuron can cause irritation to mucous membrane, skin and eyes and in the bloodstream interacts with hemoglobin forming metahemoglobin causing loss of consciousness and abnormalities in liver and spleen $[5,6]$. Due to persistence in the environment and mobility of diuron, it has been found as a contaminant in both surface and groundwater. Furthermore, once degraded into four major metabolites including $N^{\prime}-(3,4-$

\footnotetext{
* Corresponding author at: Departamento de Química, Universidade Estadual de Londrina (UEL), Rod. Celso Garcia Cid, PR 445 Km 380, Campus Universitário, Londrina, PR CEP 86051-990, Brazil.

E-mail address: ctarleyquim@yahoo.com.br (C.R.T. Tarley).
}

dichlorophenyl)- $N$-methylurea (DCPMU), 3,4-dichlorophenylurea (DCPU), 3,4-dichloroaniline (DCA) and $N^{\prime}$-(3-chlorophenyl)- $N$ methylurea (MCPMU) the concern to human health persists, once these metabolites are likewise pollutants with regard to diuron [4]. Therefore, monitoring studies regarding the detection/adsorption of diuron from natural water samples is of paramount importance to avoid human exposure to drinking water. For these reasons, the maximum allowed levels of diuron in drinking water established by the European Community (EC) and Environmental Protection Agency (EPA) have been 0.5 and $10.0 \mu \mathrm{g} \mathrm{L}{ }^{-1}$, respectively [7-9]. Several adsorbent materials for adsorption of diuron from aqueous medium have been reported, such as, activated carbon [10], surfactantmodified clay [11], natural soil [12], natural adsorbent (seeds of fruit) [13], carbon nanotubes [14], and hypercrosslinked polymers [15]. In general, these materials have promoted great differences on adsorption capacity ranging $0.012-45 \mathrm{mg} \mathrm{g}^{-1}$, with better adsorption for the carbonaceous materials. In spite of the most of these materials presenting good adsorption their selectivity is limited. In this sense, adsorbents prepared through chemical imprinting technology have widely been known in the field of separation 
science with outstanding performance for improving the adsorption process at solid/solution interfaces and selectivity of different pollutants $[16,17]$. When the target analyte is a molecule, the adsorbent is named as molecularly imprinted polymer (MIP) and its synthesis involves arranging of monomers around a template molecule forming a complex with subsequent copolymerization of a cross-linking agent through covalent or noncovalent bonds. Removal of template leaves back selectivity cavities whose shape, size and arrangement of functional groups correspond to that of the template molecule [18]. Although considerable progresses have been achieved, the use of phenylurea herbicide-selective polymer prepared through chemical imprinting technology ion in the field of separation science is in its infancy [19]. The application of MIP for the adsorption of phenylurea herbicides has been described only for isoproturon (3-(4-isopropylphenyl)-1,1-dimethylurea), linuron (3-(3-4,dichlorophenyl-1-methoxy-1-methylurea) and fenuron (1,1-dimethyl-3-pheynylurea) by using $\mathrm{N}$-(4-isopropylphenyl)- $\mathrm{N}^{\prime}$ butyleneurea as a dummy template or 2-(trifluoromethyl)-acrylic acid as functional monomer [20-22].

Therefore, the aim of this work was to synthesize molecularly imprinted polymers for the selective recognition of diuron in binding assays. For this task, two inexpensive and common monomers (methacrylic acid or acrylic acid) were employed in the MIP synthesis. In order to check the efficiency of molecularly imprinted polymers $\left(\mathrm{MIP}_{\mathrm{MA}}\right.$ and $\left.\mathrm{MIP}_{\mathrm{AA}}\right)$ towards selective adsorption of diuron, competitive adsorption studies, kinetic and isothermal assays using the nonimprinted polymers were carried out by batch technique. The polymers were also characterized by Fourier transform infrared spectra (FT-IR), scanning electron microscopy (SEM) and nitrogen adsorption-desorption assays.

\section{Experimental}

\subsection{Apparatus}

The concentrations of diuron were measured by high performance liquid chromatograph model 20A (Shimadzu®, Tokyo, Japan) equipped with a diode array detector SPD-20A operated at $225 \mathrm{~nm}$, an automatic sampler and a degasser DGU-20A $A_{5}$. The stationary phase constituted of reverse phase Pack CLC-ODS column $\left(\mathrm{C}_{18}\right)$. All the samples analyzed by chromatographic system were filtered through a $0.45 \mu \mathrm{m}$ Nylon ${ }^{\circledR}$ membrane daily. The mobile phase consisted of acetonitrile (ACN) and $\mathrm{H}_{2} \mathrm{O}(75: 30 \mathrm{v} / \mathrm{v})$ operated under isocratic model. The morphology of the molecularly imprinted polymers and non-imprinted polymers was evaluated by scanning electron microscopy (SEM), using a JEOL $®$ JSM7500F microscope (Tokyo, Japan). The samples were initially dispersed in double-sided tape coated with a thin gold layer using a Bal-Tec SDC SputternCoatter equipment (New York, USA) prior to analysis. The infrared spectra were recorded in an obtained in a Fourier transform infrared spectrophotometer model GX PerkinElmer ${ }^{\circledR}$ Spectrum (New Jersey, USA) in the $4000-400 \mathrm{~cm}^{-1}$ region with a resolution of $4 \mathrm{~cm}^{-1}$, by means of using the $\mathrm{KBr}$ pellet conventional method. The specific surface area was determined from adsorption isotherms according to the Brunauer-Emmett-Teller (BET) method, while the average pore diameter and average pore volume were estimated by the Barrett-JoynerHalenda (BJH) method based on nitrogen adsorption experiments using a Micromeritics ${ }^{\circledR}$ GEMINI-VII surface area analyzer (Norcross, USA). A Metrohm ${ }^{\circledR}$ pH 827 lab digital pH meter (Herisau, Switzerland) was used for $\mathrm{pH}$ measurements. The batch rebinding assays were performed in a rotary mixer operated at $30 \mathrm{rpm}$ (Phoenix, Brazil).

\subsection{Reagents and solutions}

All reagents used were of analytical grade or HPLC all solutions were prepared in deionized water from a Milli-Q (Direct-0.3) purification system (resistivity $\geq 18 \mathrm{M} \Omega, 25^{\circ} \mathrm{C}$ ). The monomers (methacrylic acid and acrylic acid), initiator 2,2'-azobis-isobutyronitrile (AIBN), cross-linking reagent trimethylolpropanetrimethacrylate (TRIM), diuron, carbofuran, acetonitrile (ACN), and methanol $(\mathrm{MeOH})$ were purchased from SigmaAldrich ${ }^{\circledR}$ (Steinheim, Germany) and used without further purification. Sodium hydroxide, acetic acid, hydrochloric acid and sodium dihydrogen phosphate were purchased from Synth ${ }^{\circledR}$ (Diadema, Brazil). Working standard solutions of diuron at $2.1 \times 10^{-5} \mathrm{~mol} \mathrm{~L}^{-1}$

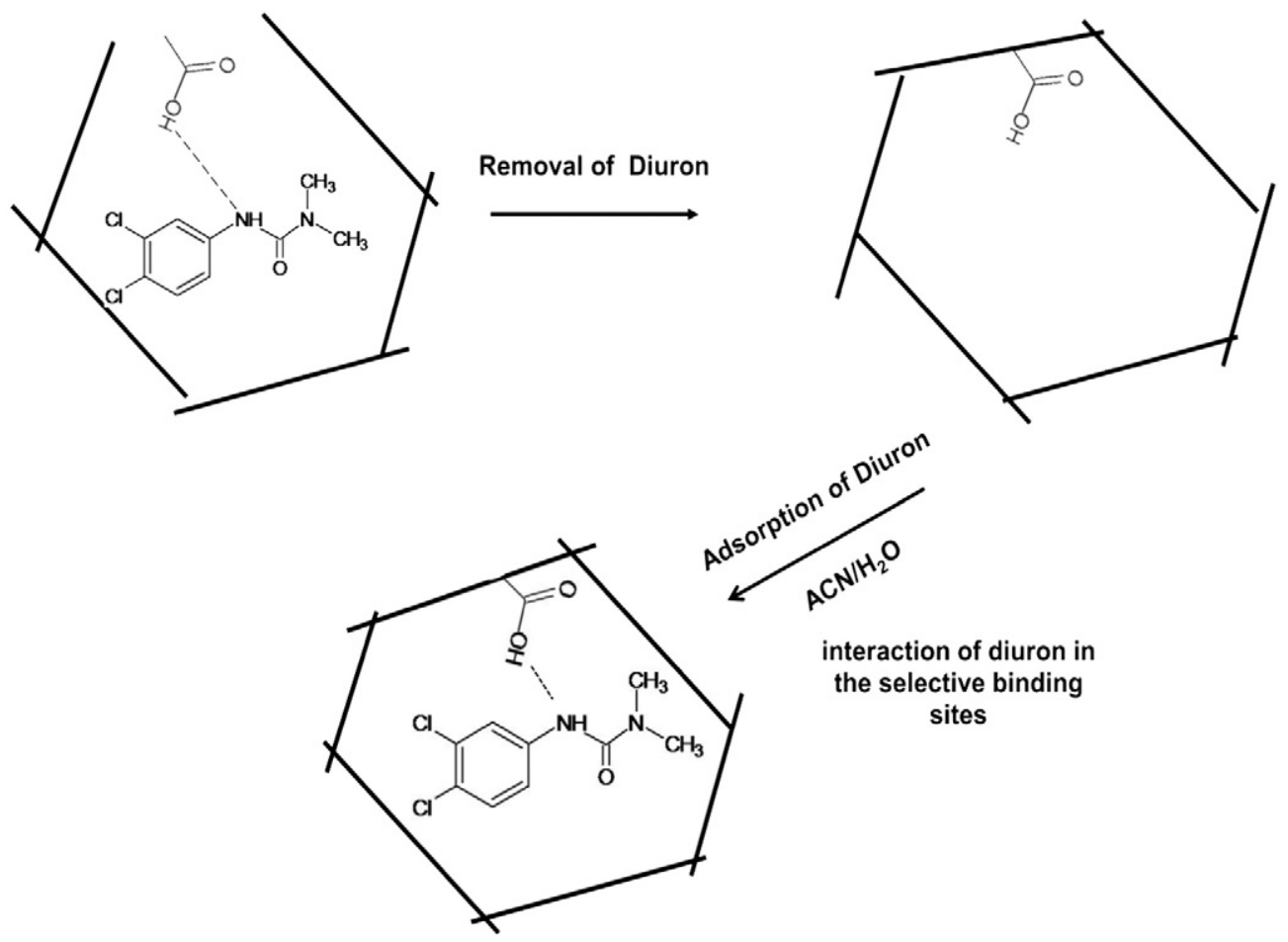

Fig. 1. Schematic illustration of imprinting process of the $\mathrm{MIP}_{\mathrm{MA}}$ for diuron and interaction with selective binding sites. 
concentration were prepared dissolving $0.5 \mathrm{mg}$ in this compound in $100 \mathrm{~mL}$ deionized water.

\subsection{Molecularly imprinted polymer syntheses}

The synthesis of molecularly imprinted poly(methacrylic acidtrimethylolpropanetrimethacrylate) ( $\mathrm{MIP}_{\mathrm{MA}}$ ) and molecularly imprinted poly(acrylic acid-trimethylolpropanetrimethacrylate) $\left(\right.$ MIP $\left._{\mathrm{AA}}\right)$, as well as its respective blank polymers (NIP) were performed through bulk polymerization technique in accordance with previous synthesis with minor modifications [23,24]. For this task, firstly $1.0 \times 10^{-4} \mathrm{~mol}$ of diuron (template) was dissolved in $6.0 \mathrm{~mL}$ of porogenic solvent (acetonitrile) in a $30 \mathrm{~mL}$ thick-walled glass tube. Next, $4 \times 10^{-4} \mathrm{~mol}$ of monomer (methacrylic acid or acrylic acid), $2 \times 10^{-3} \mathrm{~mol}$ of TRIM and $6.1 \times 10^{-5} \mathrm{~mol}$ of AIBN (radical initiator) were added to the mixture. The glass tube was purged with nitrogen for $8 \mathrm{~min}$ and after this step, it was sealed with parafilm. The polymerization was carried out at $60{ }^{\circ} \mathrm{C}$ in a water bath for a period of $24 \mathrm{~h}$. After polymerization, the glass tube was crushed, and the polymer was mechanically ground in a mortar, sieved and subjected to several washings in a volume of $100.0 \mathrm{~mL}$ methanol:acetic acid $(9: 1, v / v)$ in Soxhlet system for a period of $72 \mathrm{~h}$ in order to assure the total extraction of the analyte, which was monitored by high performance liquid chromatography (HPLC) [25]. The control polymers (NIP) were prepared in similar procedure as MIP, except by the addition of the template. The schematic illustration of imprinting process of the $\mathrm{MIP}_{\mathrm{MA}}$ for diuron and interaction with selective binding sites are depicted in Fig. 1.

\subsection{Adsorption kinetics}

In order to determine the influence of contact time on the adsorption of diuron onto polymers as well to understand the adsorption mechanism and the rate-controlling steps, a set of batch experiments were carried out. Aliquots $\left(5.0 \mathrm{~mL}\right.$ ) of diuron standard at $100 \mathrm{mg} \mathrm{L}^{-1}$ concentration prepared in $0.05 \mathrm{~mol} \mathrm{~L}^{-1}$ phosphate:acetonitrile $(1: 2, v / v)$ were mixed with $30.0 \mathrm{mg}$ of MIP or NIP in a screw capped glass flask and stirred in a rotary mixer operated at $30 \mathrm{rpm}$. The stirring time was evaluated from 10 up to 240 min and after each time, the supernatant was taken, filtered through a $0.45 \mu \mathrm{m}$ Nylon ${ }^{\circledR}$ membrane and analyzed by HPLC. The content of diuron adsorbed onto the MIP and NIP was determined according to Eq. (1).

$\mathrm{Q}_{\mathrm{t}}=\frac{\left(\mathrm{C}_{\text {initial }}-\mathrm{C}_{\text {final }}\right) \mathrm{V}}{\mathrm{m}}$

where $C_{\text {initial }}$ and $C_{\text {final }}$ are the initial and final concentrations of diuron, respectively $\left(\mathrm{mg} \mathrm{L}^{-1}\right)$, determined by HPLC; $\mathrm{V}$ is the volume of solution (L); and $\mathrm{m}$ is the mass of the polymer $(\mathrm{g})$. To the experimental kinetic adsorption data, different adsorption kinetic models were applied as follows: pseudo-first-order, pseudo-second order, Elovich and intraparticle diffusion [26]. These models provide a valuable insight into the controlling mechanism of the adsorption process.

\subsection{Adsorption isotherm}

Adsorption isotherms were built to achieve the maximum adsorption capacities (MAC) of polymers towards diuron, as well as to obtain a better insight into the distribution of diuron between the liquid and solid phases under equilibrium condition. A set of experiments were performed by stirring $30.0 \mathrm{mg}$ of MIP or NIP in a screw capped glass flask in a rotary mixer operated at $30 \mathrm{rpm}$ in the presence of $5.0 \mathrm{~mL}$ of increasing concentration of diuron (10.0-180.0 $\mathrm{mg} \mathrm{L}^{-1}$ ) prepared in
Table 1

Textural data obtained for polymers (MIP and NIP).

\begin{tabular}{llll}
\hline Polymers & $\begin{array}{l}\text { Surface area }\left(\mathrm{cm}^{2}\right. \\
\left.\mathrm{g}^{-1}\right)\end{array}$ & $\begin{array}{l}\text { Average pore volume } \\
\left(\mathrm{cm}^{3} \mathrm{~g}^{-1}\right)\end{array}$ & $\begin{array}{l}\text { Average pore diameter } \\
(\mathrm{nm})\end{array}$ \\
\hline MIP $_{\mathrm{MA}}$ & 861 & 0.67 & 6.3 \\
NIP $_{\mathrm{MA}}$ & 834 & 0.31 & 4.3 \\
MIP $_{\mathrm{AA}}$ & 275 & 0.10 & 5.2 \\
NIP $_{\mathrm{AA}}$ & 250 & 0.06 & 3.7 \\
\hline
\end{tabular}

$\mathrm{MA}=$ methacrylic acid, $\mathrm{AA}=$ acrylic acid.

$0.05 \mathrm{~mol} \mathrm{~L}^{-1}$ phosphate:acetonitrile medium $(1: 2, v / v)$ at $\mathrm{pH} 7.0$ for $180 \mathrm{~min}$. After stirring time, the supernatant was taken, filtered through a $0.45 \mu \mathrm{m}$ Nylon ${ }^{\circledR}$ membrane and analyzed by HPLC and the adsorbed amount of diuron at equilibrium under a wide diuron concentration was calculated by following Eq. (2):

$\mathrm{Q}_{\mathrm{e}}=\frac{\left(\mathrm{C}_{\text {initial }}-\mathrm{C}_{\text {equilibrium }}\right) \mathrm{V}}{\mathrm{m}}$

where $C_{\text {initial }}$ and $C_{\text {equilibrium }}$ are the initial and equilibrium concentrations of diuron, respectively ( $\mathrm{mg} \mathrm{L}^{-1}$ ), determined by HPLC; $\mathrm{V}$ is the volume of solution $(\mathrm{L})$; and $\mathrm{m}$ is the mass of the polymer $(\mathrm{g})$. The experiments of isotherm adsorption were carried out in triplicate. The data were fitted to non-linear models Langmuir, Freundlich, Langmuir-Freundlich for one site, Langmuir-Freundlich for two sites and Temkin [27-29].

\subsection{Selectivity for binding of diuron}

In order to evaluate the molecular imprinting effect created in the polymers, a set of experiments involving competitive adsorption of diuron with other herbicides by the MIP was compared to the corresponding NIP. Under equilibrium time binding experiments (180 min), $30 \mathrm{mg}$ of MIP or NIP were stirred with ternary solutions of diuron/carbofuran/ 2,4-D prepared in phosphate:acetonitrile medium $(1: 2, v / v)$ at $\mathrm{pH} 7.0$. Different concentrations of herbicides were tested: $10,25,50,75$ and $100 \mathrm{mg} \mathrm{L}^{-1}$. From the competitive adsorption of ternary solutions, the distribution constant $\left(\mathrm{K}_{\mathrm{d}}\right)$ was calculated by the following (Eqs. (3), (4) and (5)) [30].

$\mathrm{K}_{\mathrm{d}}=\frac{\left(\mathrm{C}_{\text {initial }}-\mathrm{C}_{\text {equilibrium }}\right)}{\mathrm{C}_{\text {equilibrium }}} \frac{\mathrm{V}}{M}$,

where $C_{\text {initial }}$ and $C_{\text {equilibrium }}$ are the initial and equilibrium concentrations of diuron and other herbicides $\left(\mathrm{mg} \mathrm{L}^{-1}\right), V$ is the solution volume

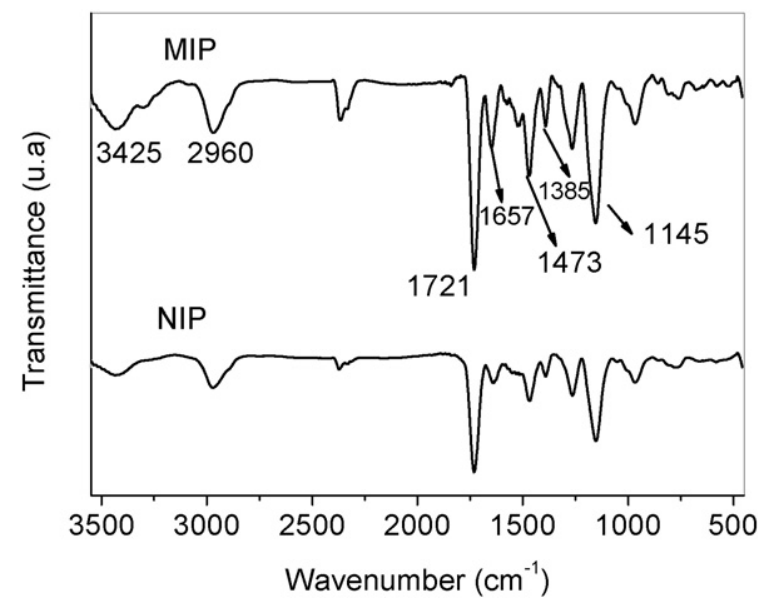

Fig. 2. FT-IR spectra of $\mathrm{MIP}_{\mathrm{MA}}$ and $\mathrm{NIP}_{\mathrm{MA}}$. 
(L), and $M$ is the polymer (MIP and NIP) mass (mg). Selectivity coefficients for diuron relative to competitor herbicides are defined as in Eqs. (4) and (5).

$$
\begin{aligned}
& \mathrm{k}_{\mathrm{MIP}}=\frac{\mathrm{K}_{\mathrm{d}}(\text { diuron })}{\mathrm{K}_{\mathrm{d}}(\mathrm{CH})} \\
& \mathrm{k}_{\mathrm{NIP}}=\frac{\mathrm{K}_{\mathrm{d}}(\text { diuron })}{\mathrm{K}_{\mathrm{d}}(\mathrm{CH})}
\end{aligned}
$$

where $\mathrm{K}_{\mathrm{d}}$ and $\mathrm{K}_{\mathrm{d}}(\mathrm{CH})$ are distribution constant of diuron and competitor herbicides, respectively. From Eqs. (4) and (5) and using $10 \mathrm{mg} \mathrm{L}^{-1}$ of herbicides, the relative selectivity coefficient $\mathrm{K}^{\prime}$ was defined as in Eq. (6).

$$
\text { (5) } \quad \mathrm{k}^{\prime}=\frac{\mathrm{k}_{\mathrm{MIP}}}{\mathrm{k}_{\mathrm{NIP}}}
$$

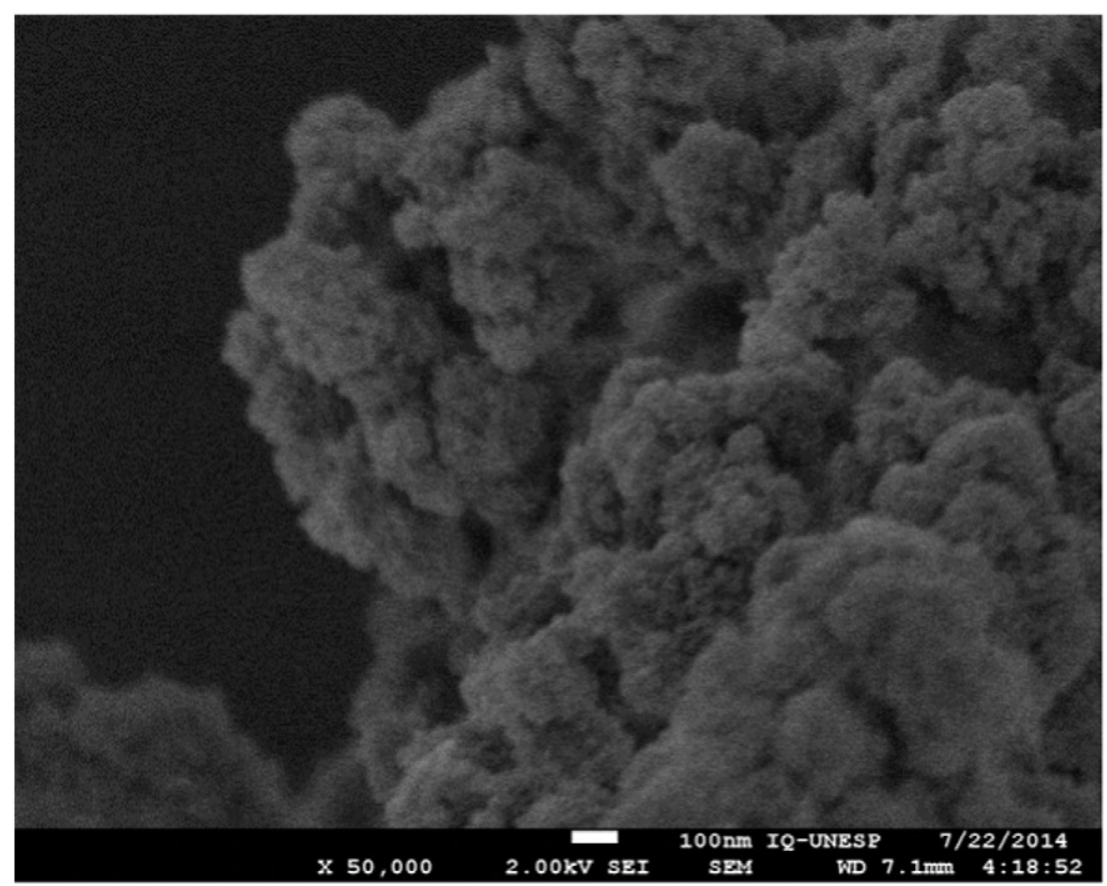

(a)

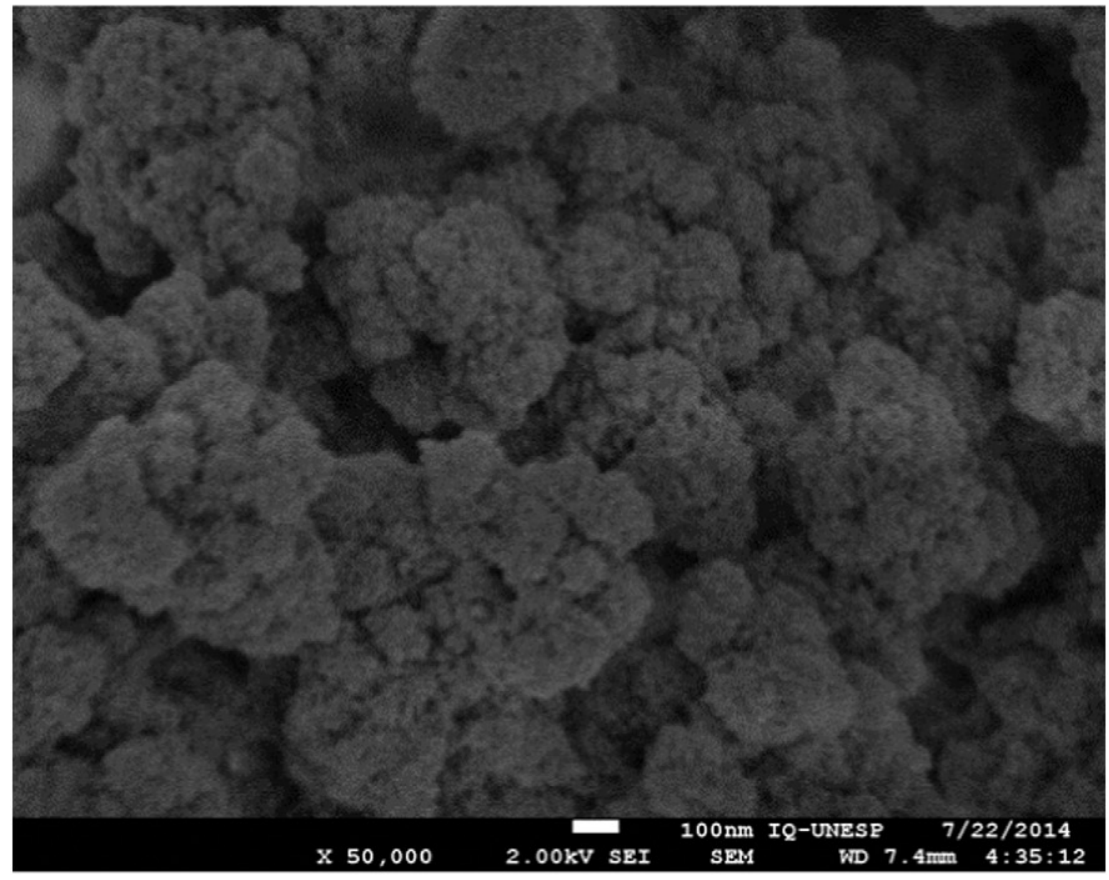

(b)

Fig. 3. SEM images of $\mathrm{MIP}_{\mathrm{MA}}$ (a) and $\mathrm{NIP}_{\mathrm{MA}}$ (b). 


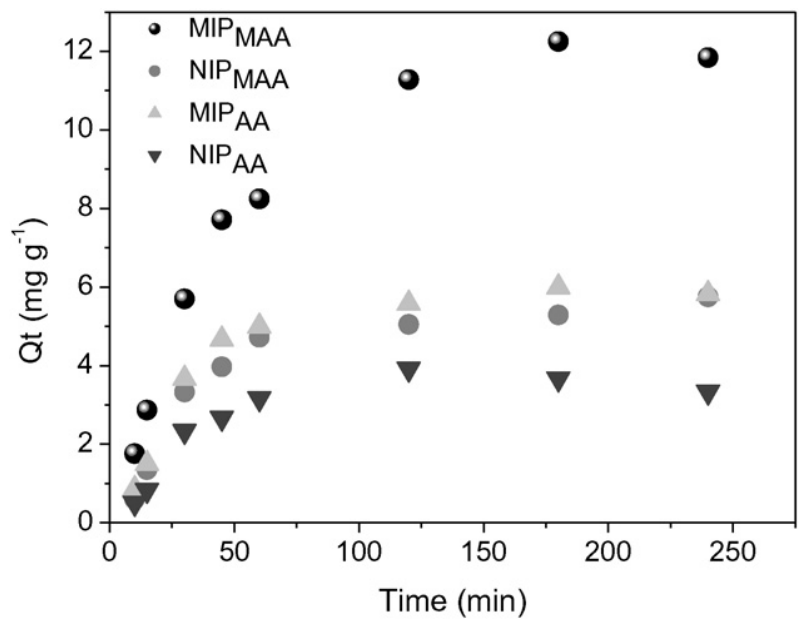

Fig. 4. Influence of stirring time on the diuron adsorption onto $\mathrm{MIP}_{\mathrm{MA}}, \mathrm{NIP}_{\mathrm{MA}}, \mathrm{MIP}_{\mathrm{AA}}$ and $\mathrm{NIP}_{\mathrm{AA}}$.

\section{Results and discussion}

\subsection{Textural data of polymers}

Table 1 presents the results of nitrogen adsorption isotherms for the polymers. All the polymers are mesoporous showing average pore diameter in the range of 2-50 $\mathrm{nm}$ [31]. It was observed that the obtained surface areas of polymers synthesized with methacrylic acid as a functional monomer were higher than the ones achieved for acrylic acid, thus showing the influence of functional monomers on the textural data. This difference can be ascribed to solubility of methacrylic and acrylic acids in the porogenic solvent (acetonitrile). It is well known that acrylic acid is more polar than methacrylic acid, as well as the acetonitrile is more polar than the methacrylic acid. Therefore, it is plausible to infer a higher solubility of acrylic acid in acetonitrile when compared to methacrylic acid, and as a consequence, the removal of solvent from the interstices of polymer becomes more difficult, which justifies the reduced porosity of MIP synthesized with acrylic acid. The lowest interaction of methacrylic acid with acetonitrile may result in higher interaction with template molecule, thus creating more selective binding sites during polymer synthesis as will be further demonstrated in rebinding assays. One should note still that pore volume and average pore diameter for the MIPs were always higher than the corresponding control polymers, which clearly makes possible to identify the effect of template molecule on the porosity of polymers. On the other hand, the surface area values between MIP $\mathrm{MA}_{\mathrm{A}}$ and $\mathrm{NIP}_{\mathrm{MA}}$ were not substantially different from each other, thus suggesting that surface area was not a criterion used to ensure selectivity. Based on the best textural data

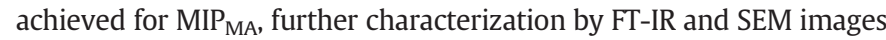
were performed only for this polymer and its corresponding nonimprinted polymer.

\subsection{FT-IR spectra of MIP $M A$ and NIP $M A$}

Fig. 2 shows the similarity of FT-IR spectra of MIP and NIP washed, showing that all diuron was removed from the MIP in an extraction step. Signals belonging to structure of polymer with the $\mathrm{O}-\mathrm{H}$ stretching vibration of MAA at $3425 \mathrm{~cm}^{-1}$ were found. The band at 2960 is attributed to $\mathrm{C}-\mathrm{H}$ asymmetric stretching of $-\mathrm{CH}_{2}-$ and $-\mathrm{CH}_{3}-$ in the polymer chain and EGDMA. The intense signal at $1721 \mathrm{~cm}^{-1}$ corresponds to the $\mathrm{C}=\mathrm{O}$ stretching vibration of MAA and EGDMA and the lower intensity signal observed at $1657 \mathrm{~cm}^{-1}$ is attributed to $\mathrm{OH}$ deformation (water adsorbed) [32]. The band at $1385 \mathrm{~cm}^{-1}$ is assigned to angular out-ofplane deformation of the methyl groups, while the absorption band at $1145 \mathrm{~cm}^{-1}$ can be assigned to $\mathrm{O}-\mathrm{C}(\mathrm{O})-\mathrm{C}$ stretching vibration of EGDMA [28].

\subsection{SEM images of $M I P_{M A}$ and NIP $M A$}

Scanning electron micrographs of the MIP and NIP with magnification of 50.000 times are shown in Fig. 3. It is seen that the morphological characteristics of polymers are very similar to each other with a roughness surface, which might be concluded that the presence of template

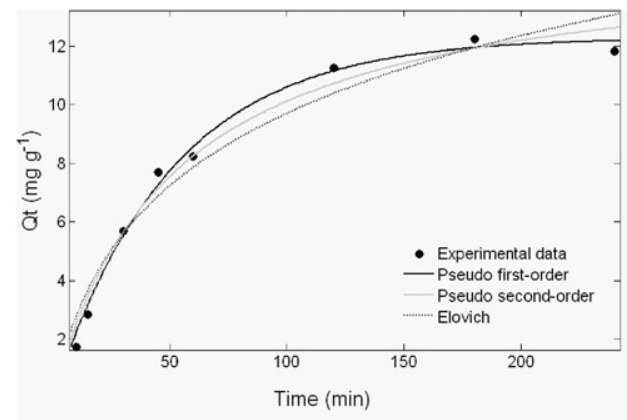

(a)

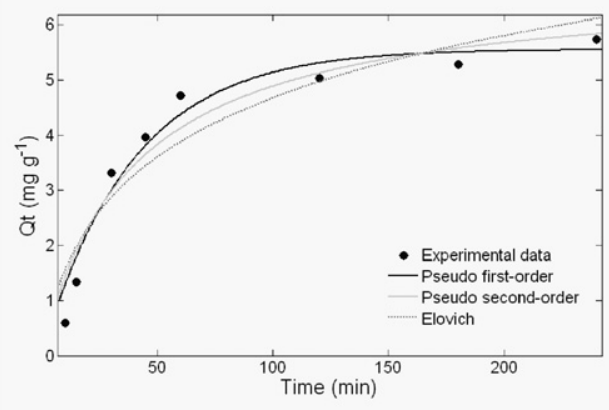

(c)

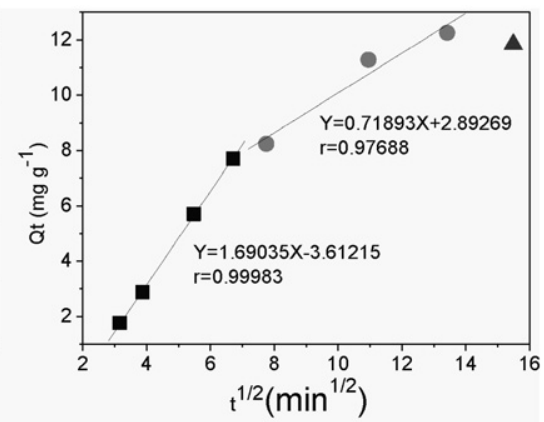

(b)

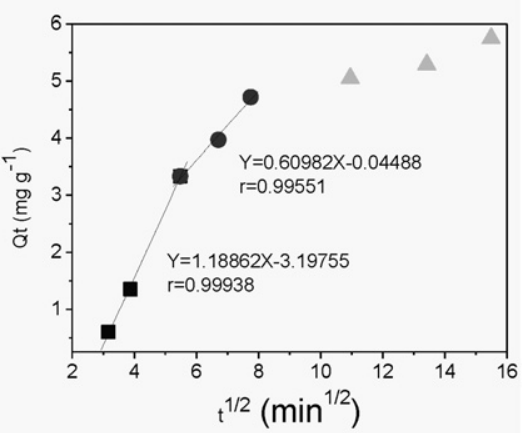

(d)

Fig. 5. Adsorption kinetic of diuron onto $\operatorname{MIP}_{\mathrm{MA}}(\mathrm{a}, \mathrm{b})$ and $\mathrm{NIP}_{\mathrm{MA}}(\mathrm{c}, \mathrm{d})$ and plots of theoretical kinetic models. 


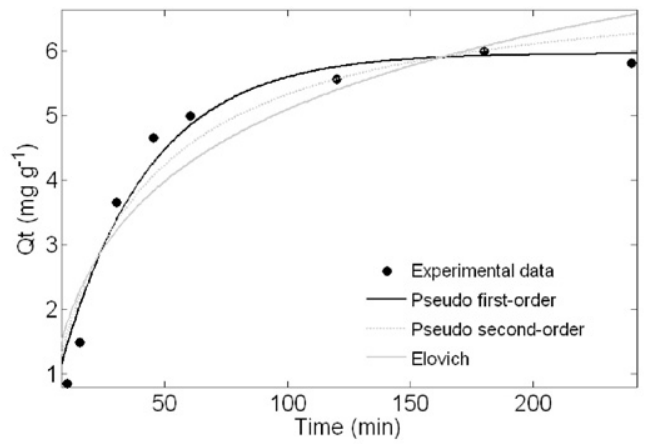

(a)

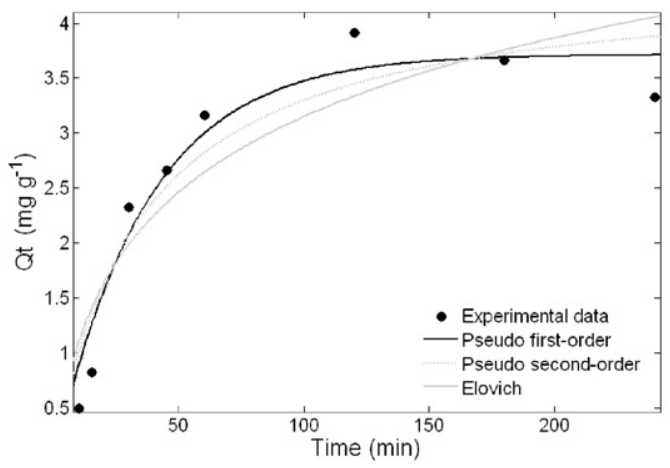

(c)

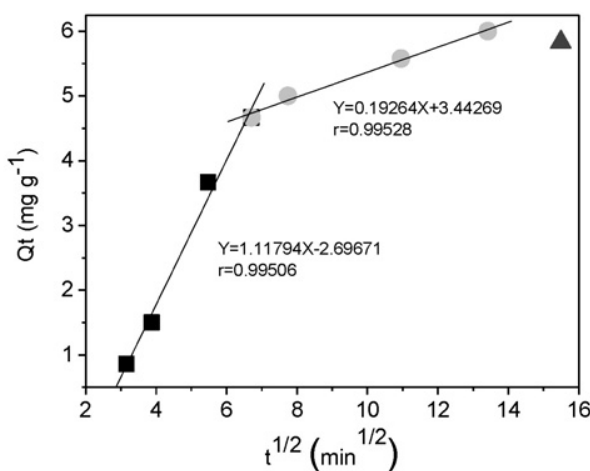

(b)

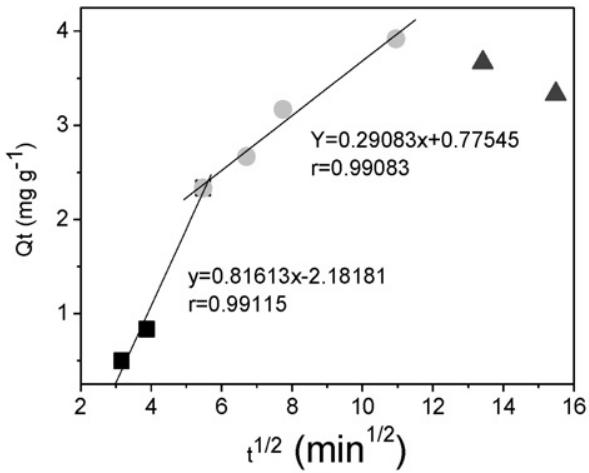

(d)

Fig. 6. Adsorption kinetic of diuron onto $\operatorname{MIP}_{\mathrm{AA}}(\mathrm{a}, \mathrm{b})$ and $\mathrm{NIP}_{\mathrm{AA}}(\mathrm{c}, \mathrm{d})$ and plots of theoretical kinetic models.

molecule in the synthesis of polymer does not influence the morphological characteristics of particles. These results corroborate the results achieved from the textural data (Table 1), where the template molecule does not exert influence on surface area, but, on the other hand, promotes increases on average pore diameter and pore volume.

\subsection{Optimization of adsorption parameters}

In order to find the best conditions of diuron extraction onto MIPMAA the effect of $\mathrm{pH}$ (4-9), adsorbent mass (10-35 mg), solvent $\left(\mathrm{H}_{2} \mathrm{O}\right.$, MeOH:0.05 $\mathrm{mol} \mathrm{L}^{-1}$ phosphate, $0.05 \mathrm{~mol} \mathrm{~L}^{-1}$ phosphate:acetonitrile, acetonitrile, $\mathrm{MeOH})$ and proportion $(v / v)(1: 1,1: 21: 3,1: 4,1: 5$ and pure solvent) were investigated in a set of batch experiments stirring the polymer with diuron solution for $180 \mathrm{~min}$. The results of these experiments indicated that by increasing the $\mathrm{pH}$, the extraction of diuron was increased and the optimum $\mathrm{pH}$ was found to be 7.0. Under the $\mathrm{pH}$ range studied (4-9) the diuron is in its molecular form once its pKa is 13.55. Therefore, it is plausible to infer that diuron interacts with monomer residues of methacrylic acid ( $\mathrm{pKa}=4.66$ ) [33] by means of hydrogen bonding or dipole-dipole forces. Higher adsorption of diuron onto MIP $_{\text {MAA }}$ occurred in $0.05 \mathrm{~mol} \mathrm{~L}^{-1}$ phosphate:acetonitrile $(1: 2, v / v)$ medium, thus indicating clearly the effect of porogenic solvent on the adsorptive properties of MIP. The best MIP mass in the batch assays was found to be $35 \mathrm{mg}$. Based on the achieved results the following optimum condition of diuron extraction on the MIP $\mathrm{MAA}_{\mathrm{AA}}$ was chosen: $\mathrm{pH} 7.0$, $0.05 \mathrm{~mol} \mathrm{~L}^{-1}$ phosphate:acetonitrile $(1: 2, v / v)$ as solvent and MIP mass of $35 \mathrm{mg}$.

\subsection{Adsorption kinetics}

The adsorption kinetic studies demonstrated that the adsorption equilibrium is reached in 180 min for MIP $_{\text {MAA }}$, NIP $P_{\text {MAA }}$ and MIP $A$ A with

Table 2

Kinetic parameters for the adsorption of diuron onto polymers. $\mathrm{Q}_{\exp }=12.23 \mathrm{mg} \mathrm{g}^{-1}$ for $\mathrm{MIP}_{\mathrm{MAA}}, 5.25 \mathrm{mg} \mathrm{g}^{-1}$ for NIP $_{\mathrm{MAA}}, 5.98 \mathrm{mg} \mathrm{g}^{-1}$ for $\mathrm{MIP}_{\mathrm{AA}}$ and $3.67 \mathrm{mg} \mathrm{g}^{-1}$ for $\mathrm{NIP}_{\mathrm{AA}}$.

\begin{tabular}{|c|c|c|c|c|c|c|c|c|c|c|c|c|c|c|c|c|}
\hline \multirow[b]{3}{*}{ Polymers } & \multicolumn{4}{|c|}{ Pseudo first-order } & \multicolumn{4}{|c|}{ Pseudo second-order } & \multicolumn{4}{|c|}{ Elovich } & \multicolumn{4}{|c|}{ Intraparticle diffusion } \\
\hline & \multicolumn{4}{|c|}{$\mathrm{Q}_{\mathrm{t}}=\mathrm{Q}_{\mathrm{e}}\left(1-\mathrm{e}^{-\mathrm{kt}}\right)$} & \multicolumn{4}{|c|}{$\mathrm{Q}_{\mathrm{t}}=\frac{\mathrm{kQ}_{\mathrm{e}}{ }^{2} \mathrm{t}}{1+\mathrm{kQ}_{\mathrm{e}} \mathrm{t}}$} & \multicolumn{4}{|c|}{$\mathrm{Q}_{\mathrm{t}}=\frac{2.3}{\beta}, \log (1+\alpha \beta \mathrm{t})$} & \multicolumn{4}{|c|}{$\mathrm{Q}_{\mathrm{t}}=\mathrm{k}_{\mathrm{id}} \mathrm{t}^{1 / 2}+\mathrm{C}_{\mathrm{i}}$} \\
\hline & $\mathrm{k}_{1}$ & $\mathrm{Q}_{\mathrm{e}}$ & $\mathrm{R}^{2}$ & RMSE & $\mathrm{k}_{2}$ & $\mathrm{Q}_{\mathrm{e}}$ & $\mathrm{R}^{2}$ & RMSE & $\beta$ & $\alpha$ & $\mathrm{R}^{2}$ & RMSE & $\mathrm{K}_{\mathrm{id}}$ & $C_{i}$ & $\mathrm{R}^{2}$ & RMSE \\
\hline \multirow[t]{2}{*}{$\mathrm{MIP}_{\mathrm{MAA}}$} & 0.02 & 12.3 & 0.99 & 0.37 & 0.01 & 15.3 & 0.98 & 0.61 & 0.58 & 0.4 & 0.96 & 0.91 & 1.69 & 3.61 & 0.99 & 0.06 \\
\hline & & & & & & & & & & & & & 0.72 & 2.89 & 0.98 & 0.63 \\
\hline \multirow[t]{2}{*}{$\mathrm{NIP}_{\mathrm{MAA}}$} & 0.02 & 5.56 & 0.96 & 0.41 & 0.01 & 6.77 & 0.93 & 0.52 & 0.24 & 0.25 & 0.89 & 0.67 & 1.19 & 3.19 & 0.99 & 0.07 \\
\hline & & & & & & & & & & & & & 0.61 & 0.04 & 0.99 & 0.09 \\
\hline \multirow[t]{2}{*}{$\mathrm{MIP}_{\mathrm{AA}}$} & 0.03 & 5.97 & 0.96 & 0.40 & 0.01 & 7.15 & 0.93 & 0.56 & 0.58 & 0.31 & 0.87 & 0.76 & 1.12 & 2.69 & 0.99 & 0.22 \\
\hline & & & & & & & & & & & & & 0.19 & 3.44 & 0.99 & 0.07 \\
\hline \multirow[t]{2}{*}{$\mathrm{NIP}_{\mathrm{AA}}$} & 0.03 & 3.72 & 0.94 & 0.34 & 0.01 & 4.34 & 0.89 & 0.46 & 0.93 & 0.19 & 0.82 & 0.58 & 0.82 & 2.18 & 0.99 & 0.18 \\
\hline & & & & & & & & & & & & & 0.29 & 0.77 & 0.99 & 0.11 \\
\hline
\end{tabular}

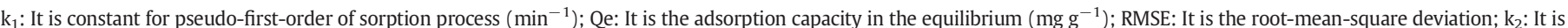

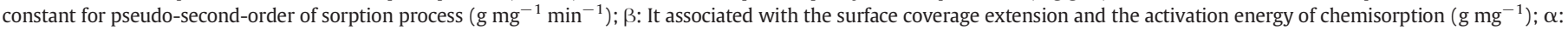

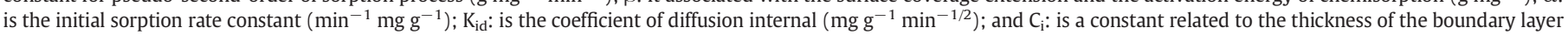
$\left(\mathrm{mg} \mathrm{g}^{-1}\right)$. 


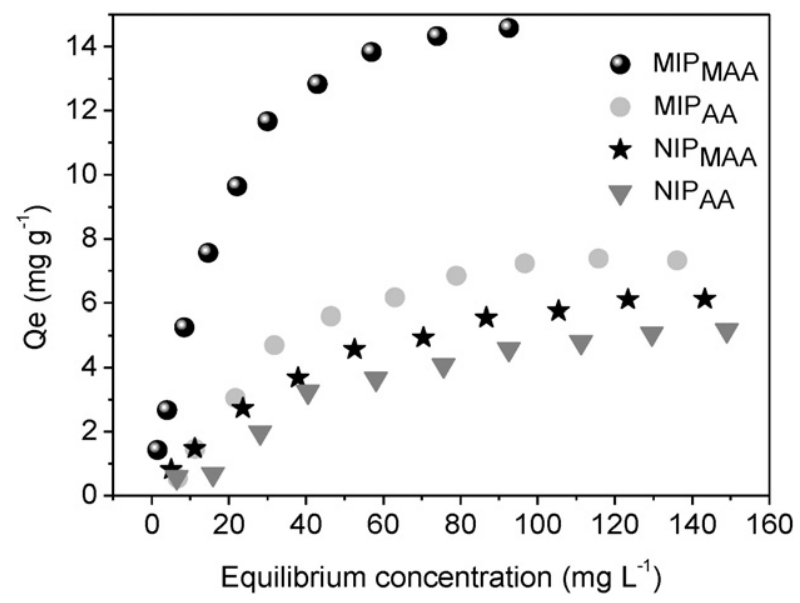

Fig. 7. Adsorption isotherm of diuron onto $\mathrm{MIP}_{\mathrm{MA}}, \mathrm{NIP}_{\mathrm{MA}}, \mathrm{MIP}_{\mathrm{AA}}$ and $\mathrm{NIP}_{\mathrm{AA}}$.

experimental adsorption capacity $\left(Q_{e}\right)$ of $12.30,5.27$ and $5.99 \mathrm{mg} \mathrm{g}^{-1}$, respectively (Fig. 4). The NIPAA presented equilibrium time of $120 \mathrm{~min}$ with adsorptive capacity of $3.89 \mathrm{mg} \mathrm{g}^{-1}$. The higher adsorptive capacity of the MIPs compared to the respective NIPs can be attributed to the high affinity of diuron by selective cavities, while adsorption onto the NIP occurs only in non-selective sites. For interpretation of kinetic experimental data the non-linear pseudo first-order [34], non-linear pseudo second-order [35], non-linear Elovich [36] and intraparticle diffusion [37] models were evaluated, whose fit are shown in Figs. 5 and 6 for the polymers synthesized with methacrylic acid and acrylic acid, respectively. The corresponding results were tabulated in Table 2 . The validity of the models was checked by the determination coefficients $\left(R^{2}\right)$, similarity of Qe experimental with those values predicted by the models, as well as by means of root-mean-square deviation (RMSD) defined by Eq. (7).

RMSD $=\frac{\sqrt{\sum_{i=1}^{n}\left(q_{\exp }-q_{p}\right)^{2}}}{n-1}$

where $\mathrm{q}_{\exp }\left(\mathrm{mg} \mathrm{g}^{-1}\right)$ and $\mathrm{q}_{\mathrm{p}}\left(\mathrm{mg} \mathrm{g}^{-1}\right)$ are the respective experimental and predicted adsorption capacity by models. It was found that pseudo first-order and intraparticle diffusion models satisfactory described the kinetic adsorption as compared to the other models. The pseudo firstorder model assumes that the adsorption occurs at energetically homogeneous sites in the material, possibly attributed to carboxyl of methacrylic acid and acrylic acid monomers. Moreover, this model describes that the rate of adsorption is proportional to the number of unoccupied sites and does not assume that the rate-limiting step may be chemisorption, as described by pseudo second-order [34], thus showing a strong evidence that interactions of diuron with binding sites of polymers takes place by means of intermolecular forces such as hydrogen bonding or dipole-dipole forces, but not by chemisorption. The experimental kinetic adsorption cannot be considered as pseudo second-order although the determination coefficients were slightly high, once the Qe predicted by this model was different from the experimental data. Furthermore, the worst fitting of pseudo second-order model corroborates the worst fitting of Elovich model, once these models are complementary and assume that the adsorption occurs onto sites energetically heterogeneous in the adsorbent [38]. The intraparticle diffusion model may present three linear plots qt versus $t^{1 / 2}$. If intraparticle diffusion mechanism is the sole rate limiting step in the adsorption process the plot passes through the origin. On the other hand, if plot does not pass through the origin, the linear coefficient from the intraparticle diffusion model $\left(C_{i}\right)$ gives an idea of the boundary layer thickness $\left(\mathrm{mg} \mathrm{g}^{-1}\right)$. The

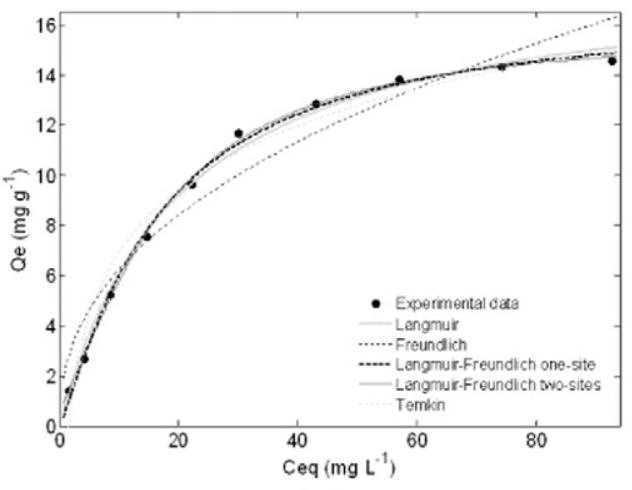

(a)

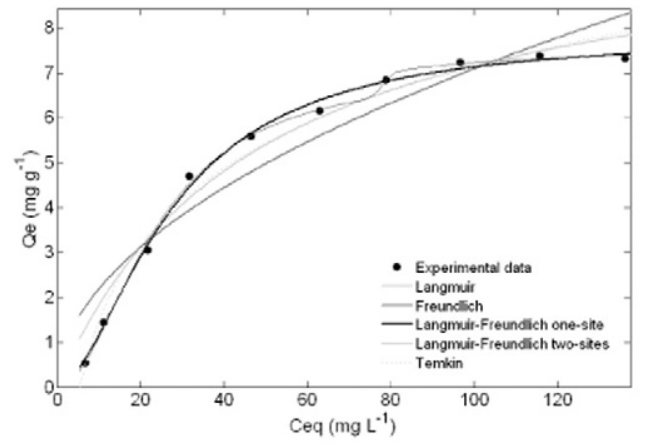

(c)

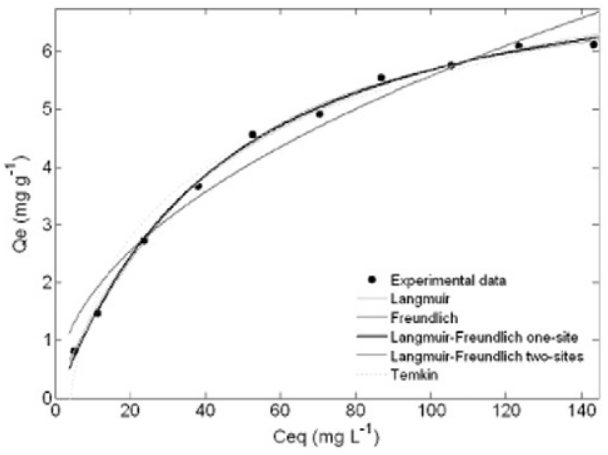

(b)

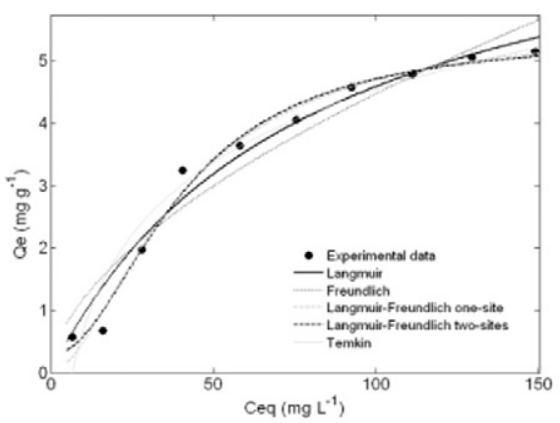

(d)

Fig. 8. Adsorption isotherm of diuron onto $\mathrm{MIP}_{\mathrm{MA}}(\mathrm{a}), \mathrm{NIP}_{\mathrm{MA}}(\mathrm{b}), \mathrm{MIP}_{\mathrm{AA}}(\mathrm{c})$ and $\mathrm{NIP}_{\mathrm{AA}}(\mathrm{d})$ and plots of theoretical isotherm models. 
Table 3

Isotherm parameters for the adsorption of diuron onto polymers. $Q_{\exp }=14.58 \mathrm{mg} \mathrm{g}^{-1}$ for

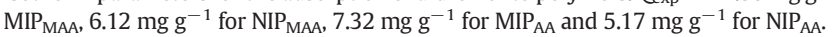

\begin{tabular}{|c|c|c|c|c|}
\hline & \multicolumn{4}{|c|}{ Polymers } \\
\hline & MIP $_{\text {MAA }}$ & $\mathrm{NIP}_{\mathrm{MAA}}$ & $\mathrm{MIP}_{\mathrm{AA}}$ & NIP $_{\text {MAA }}$ \\
\hline \multicolumn{5}{|c|}{ Non-linear Langmuir $\mathrm{Q}_{\mathrm{eq}}=\mathrm{KbC}_{\mathrm{eq}} /\left(1+\mathrm{KC}_{\mathrm{eq}}\right)$} \\
\hline K & 0.05 & 0.02 & 0.02 & 0.01 \\
\hline $\mathrm{b}$ & 18.31 & 8.36 & 10.58 & 8.21 \\
\hline $\mathrm{R}^{2}$ & 0.9949 & 0.9969 & 0.9699 & 0.9696 \\
\hline RMSE & 0.37 & 0.11 & 0.46 & 0.32 \\
\hline \multicolumn{5}{|c|}{ Non-linear Freundlich $\mathrm{Q}_{\mathrm{eq}}=\mathrm{KC}_{\mathrm{eq}}{ }^{1 / \mathrm{n}}$} \\
\hline K & 2.33 & 0.59 & 0.67 & 0.31 \\
\hline $\mathrm{n}$ & 2.33 & 2.05 & 1.96 & 1.73 \\
\hline $\mathrm{R}^{2}$ & 0.9416 & 0.9649 & 0.9077 & 0.9341 \\
\hline RMSE & 1.26 & 0.38 & 0.81 & 0.47 \\
\hline \multicolumn{5}{|c|}{ Langmuir-Freundlich for one site $\mathrm{Q}_{\mathrm{eq}}=\mathrm{b}\left(\mathrm{KC} \mathrm{eq}_{\mathrm{eq}}\right)^{\mathrm{n}_{1} / 1}+\left(\mathrm{KC}_{\mathrm{eq}}\right)^{\mathrm{n}}$} \\
\hline K & 0.06 & 0.02 & 0.04 & 0.02 \\
\hline $\mathrm{b}$ & 16.81 & 7.77 & 7.85 & 5.65 \\
\hline $\mathrm{n}$ & 1.17 & 1.11 & 1.75 & 1.71 \\
\hline $\mathrm{R}^{2}$ & 0.9971 & 0.9976 & 0.9969 & 0.9858 \\
\hline RMSE & 0.30 & 0.11 & 0.16 & 0.23 \\
\hline \multicolumn{5}{|c|}{ Langmuir-Freundlich for two sites $Q_{e q}=\frac{b_{1}\left(K_{1} C_{e q}\right)^{n_{1}}}{1+\left(K_{1} C_{e q}\right)^{n_{1}}}+\frac{b_{2}\left(K_{2} C_{e q}\right)^{n_{2}}}{1+\left(K_{2} C_{e q}\right)^{n_{2}}}$} \\
\hline $\mathrm{K}_{1}$ & 0.04 & 0.02 & 0.01 & $4.4 \times 10^{-3}$ \\
\hline $\mathrm{K}_{2}$ & 0.12 & 27.36 & 0.04 & 0.03 \\
\hline$b_{1}$ & 7.21 & 6.71 & 0.54 & 8.86 \\
\hline$b_{2}$ & 8.41 & 0.53 & 7.07 & 1.64 \\
\hline $\mathrm{n}_{1}$ & 2.14 & 1.34 & 84.66 & 0.86 \\
\hline $\mathrm{n}_{2}$ & 1.01 & 0.24 & 1.97 & 13.33 \\
\hline $\mathrm{R}^{2}$ & 0.9989 & 0.9983 & 0.9985 & 0.9963 \\
\hline RMSE & 0.24 & 0.12 & 0.15 & 0.16 \\
\hline \multicolumn{5}{|c|}{ Temkin $\mathrm{Q}_{\mathrm{eq}}=\frac{\mathrm{RT}}{\mathrm{b}_{\mathrm{T}}}, \ln \left(\mathrm{K}_{\mathrm{t}} \mathrm{C}_{\mathrm{e}}\right)$} \\
\hline $\mathrm{K}_{\mathrm{t}}$ & 0.67 & 0.18 & 0.18 & 0.15 \\
\hline $\mathrm{b}_{\mathrm{T}}$ & $0.68^{*}$ & $1.42^{*}$ & $1.00^{*}$ & $1.47^{*}$ \\
\hline $\mathrm{R}^{2}$ & 0.9728 & 0.9842 & 0.9728 & 0.9472 \\
\hline RMSE & 0.86 & 0.26 & 0.35 & 0.40 \\
\hline
\end{tabular}

In the Langmuir, Freundlich and Langmuir-Freundlich equations: $\mathrm{K}$ (Langmuir), $\mathrm{K}_{1,2}$ (Langmuir-Freundlich) $\left(\mathrm{Lg}^{-1}\right), \mathrm{K}$ (Freundlich) $\left(\mathrm{mg} \mathrm{g}^{-1}\right)\left(\mathrm{Lg}^{-1}\right)$ - adsorbate-adsorbent affinities, $b, b_{12}-$ maximum adsorption capacities $\left(\mathrm{mg} \mathrm{g}^{-1}\right)$, and $\mathrm{n}, \mathrm{n}_{12}-$ intensities or degrees of favorability for adsorption. *b: It is the Temkin constant related to heat of sorption $\left(\mathrm{kJ} \mathrm{mol}^{-1}\right)$.

second linear segment refers to the progressive adsorption inside the material by intraparticle diffusion and the third segment is the step where the equilibrium between solid phase and liquid phase is reached. As observed in Figs. 5 and 6 and Table 2, the values of the boundary layer thickness in intraparticle diffusion model different from zero indicates that adsorption of diuron onto the polymers takes place both by instant adsorption on the external surface governed by mass transfer in the external liquid film and by pore diffusion $[32,39,40]$. It is worth emphasizing that molecularly imprinted polymers have shown higher boundary layer thickness than the non-imprinted polymers, which indicates a larger number of binding sites on the external surface of the sorbent, thus favoring the diuron adsorption through external liquid film.

\subsection{Adsorption isotherm}

The Langmuir isotherm model has been well applied to experimental isotherms and admits that the adsorbent surface is uniform; there is no interaction between the adsorbate molecules and the adsorption occurs in monolayer on the surface of the adsorbent. The non-linear Langmuir equation is described by Eq. (8), where $\mathrm{Q}_{\mathrm{eq}}$ is the adsorbed amount of adsorbate per mass of adsorbent $\left(\mathrm{mg} \mathrm{g}^{-1}\right), \mathrm{K}$ is the Langmuir constant related to the rate of adsorption, $b$ is the MAC of the material and $C_{e}$ is the equilibrium concentration of adsorbate $\left(\mathrm{mg} \mathrm{L}^{-1}\right)$ [41].

$\mathrm{Q}_{\mathrm{eq}}=\mathrm{KbC}_{\mathrm{eq}} /\left(1+\mathrm{KC}_{\mathrm{eq}}\right)$.

The Freundlich isotherm has been used to describe adsorptive processes occurring in heterogeneous surfaces on which adsorption occurs in multilayer. The non-linear Freundlich equation is shown by Eq. (9), where $\mathrm{K}$ and $\mathrm{n}$ are constant related to the adsorption capacity $\left(\mathrm{L} \mathrm{mg}^{-1}\right.$ ) and the intensity of adsorption, respectively [42].

$\mathrm{Q}_{\mathrm{eq}}=\mathrm{KC}_{\mathrm{eq}}{ }^{1 / \mathrm{n}}$.

The Temkin isotherm takes into account the interaction between adsorbate-adsorbent. According to this model the heat of adsorption decreases linearly with the coverage due to interactions between the adsorbate and adsorbent. The equation of the Temkin isotherm is shown in Eq. (10), where R is the universal gas constant, $\mathrm{T}$ is the absolute temperature of solution $(\mathrm{K}), \mathrm{b}_{\mathrm{T}}$ is the Temkin constant related the

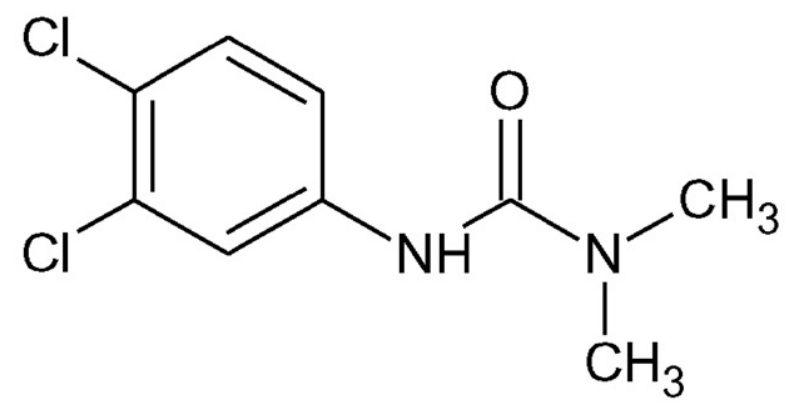

(a)

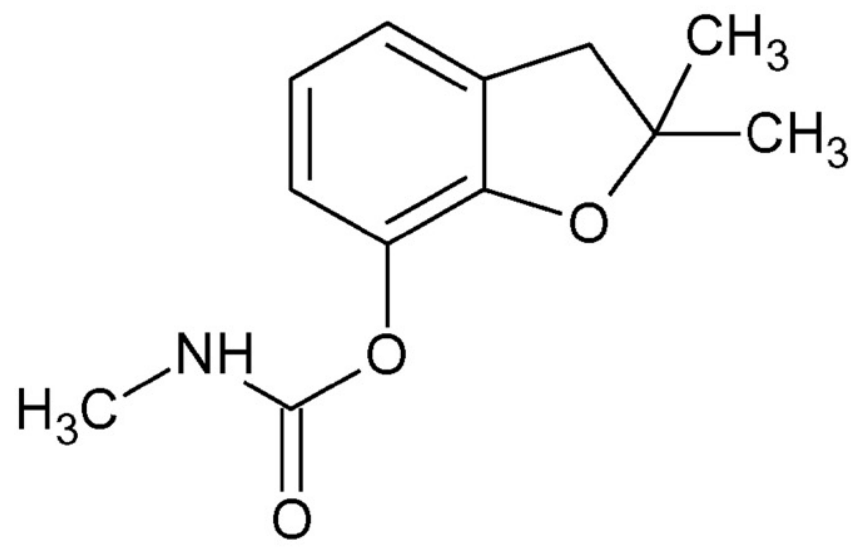

(b)

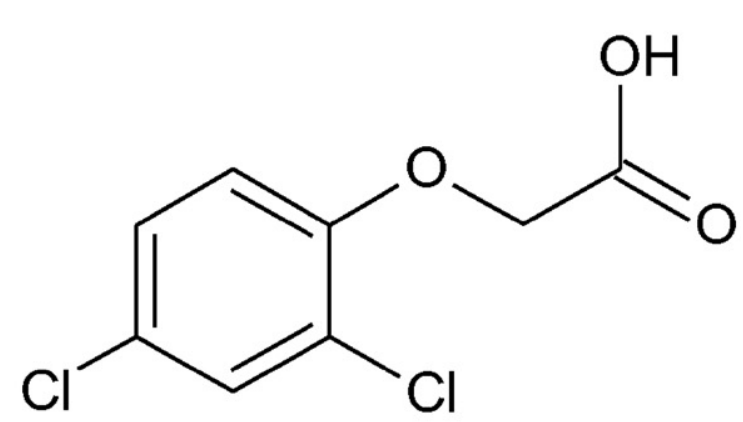

(c)

Fig. 9. Chemical structure of pesticides analyzed in the selectivity test. (a) Diuron, (c) carbofuran, and (d) 2,4-D. 


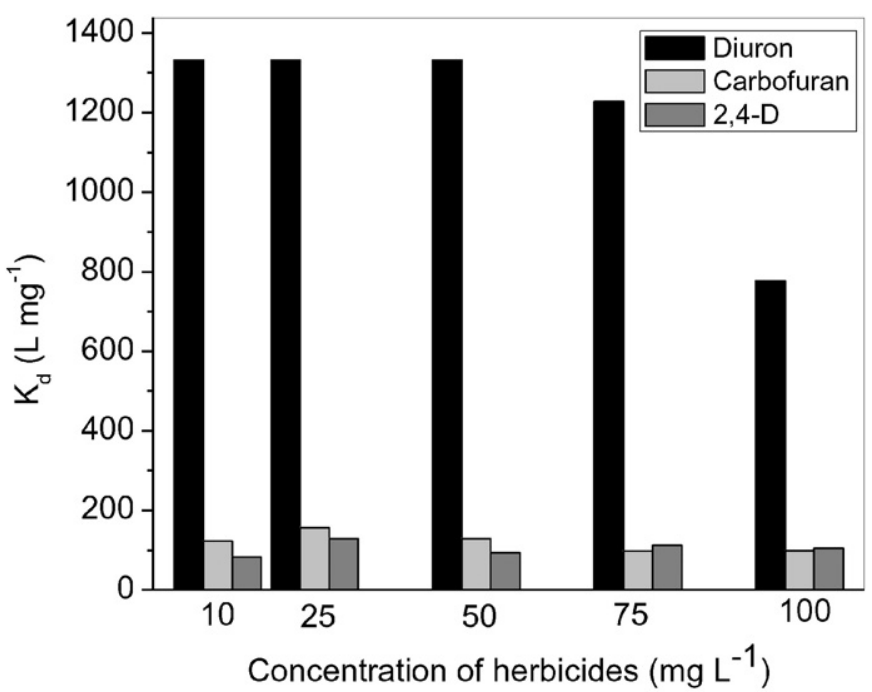

(a)

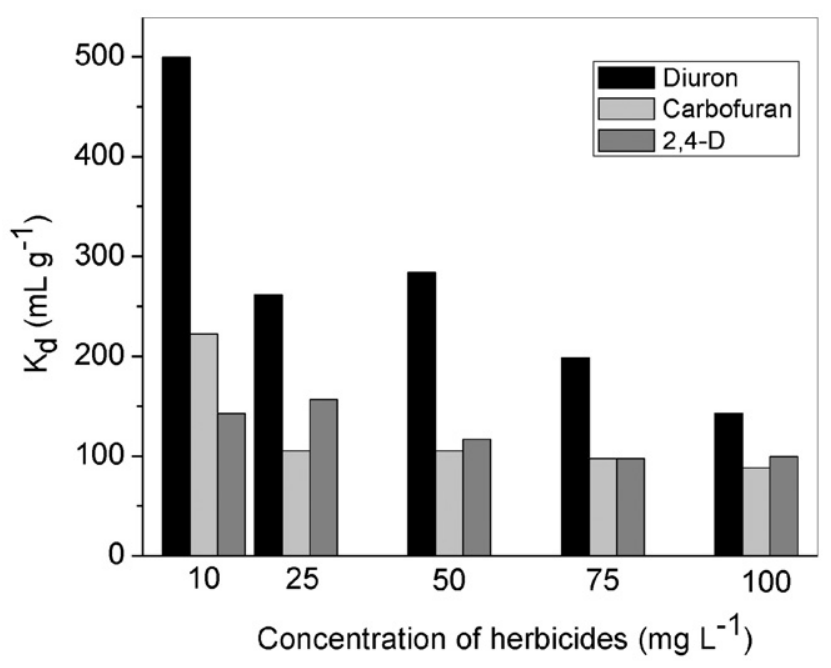

(b)

Fig. 10. Distribution coefficients $\left(K_{d}\right)$ obtained for diuron, carbofuran and 2,4-D on the $\operatorname{MIP}_{\mathrm{MA}}(\mathrm{a})$ and $\mathrm{MIP}_{\mathrm{AA}}$ (b) in ternary mixture.

adsorption heat $\left(\mathrm{kJ} \mathrm{mol}^{-1}\right)$ and $\mathrm{K}_{\mathrm{t}}$ is the Temkin isotherm constant $\left(\mathrm{g} \mathrm{L}^{-1}\right)[43]$.

$\mathrm{Q}_{\mathrm{eq}}=\frac{\mathrm{RT}}{\mathrm{b}_{\mathrm{T}}} \ln \left(K_{t} C_{e}\right)$.

The isotherm of Langmuir-Freundlich for one site (Eq. (11)), which is also known as Sip's equation, is suitable to describe both the Langmuir-type and Freundlich-type. This isotherm also allows one to evaluate the presence of heterogeneous and homogeneous binding sites based on index $n$, which can vary from 0 to 1 . When index $n$ is close to 1 , the material is homogeneous and when it is less than 1 the material is heterogeneous. Despite being very useful this model does not consider the availability of two-adsorption sites with different affinities towards adsorbate.

$\mathrm{Q}_{\mathrm{eq}}=\mathrm{b}\left(\mathrm{KC}_{\mathrm{eq}}\right)^{\mathrm{n}_{1}} / 1+\left(\mathrm{KC}_{\mathrm{eq}}\right)^{\mathrm{n}}$.

The isotherm of Langmuir-Freundlich for two sites (Eq. (12)) admits the presence of heterogeneous solid surface and describes adsorption binding interactions among adsorbing compounds considering adsorption sites with different affinities. In this model the adsorbate adsorbs mostly in the most energetic sites when these sites are fully populated followed by adsorption in the less energetic sites [44].

$\mathrm{Q}_{\mathrm{eq}}=\frac{\mathrm{b}_{1}\left(\mathrm{~K}_{1} \mathrm{C}_{\mathrm{eq}}\right)^{\mathrm{n}_{1}}}{1+\left(\mathrm{K}_{1} \mathrm{C}_{\mathrm{eq}}\right)^{\mathrm{n}_{1}}}+\frac{\mathrm{b}_{2}\left(\mathrm{~K}_{2} \mathrm{C}_{\mathrm{eq}}\right)^{\mathrm{n}_{2}}}{1+\left(\mathrm{K}_{2} \mathrm{C}_{\mathrm{eq}}\right)^{\mathrm{n}_{2}}}$.

The experimental adsorption isotherms of MIP MAA, NIP $_{\text {MAA, }}$ MIP $A$ A and NIP $_{\mathrm{AA}}$ are shown in Fig. 7. It can be observed that the MIPs had higher adsorptive maximum capacities when compared to their respective NIPs. This finding indicates that the differences on the diuron adsorption by MIP and NIP are not attributed to morphological features of polymers once the obtained data were very similar to each other as already demonstrated (Table 1 ), but mostly due to the presence of selective adsorptive sites present in the MIP. The MAC of MIP ${ }_{\text {MAA }}$ (14.58 $\mathrm{mg} \mathrm{g}^{-1}$ ) was found to be 2-fold higher when compared to the $\mathrm{MIP}_{\mathrm{AA}}$, thus suggesting higher interaction energy between methacrylic acid and diuron. As the experimental MAC obtained for MIP $\mathrm{MAA}_{\mathrm{A}}$ is higher or similar to that observed for other adsorbents from different sources, such as natural adsorbent [13], carbon nanotubes [14], activated carbon [10] and surfactant-modified clay [14] it should be admitted that synthesized polymer has satisfactory adsorptive performance.

The experimental data points compared to theoretical isotherms are displayed in Fig. 8. Among the fitted models both Langmuir-Freundlich for one site (LF-1) and Langmuir-Freundlich for two sites (LF-2) showed the best fit to the experimental data for all polymers. The good fit of these models can be rationalized on the basis of the lowest values of RMSE, satisfactory values of determination coefficients $\left(R^{2}\right)$ and similarity of Qe experimental with those values predicted by the models ( $b$ for LF-1 and the sum b1 + b2 for LF-2) (Table 3). However, as already mentioned, although LF-1 has shown good fit to the experimental data, it fails in describing the existence of two-adsorption sites with different affinities towards adsorbate. Therefore, more detailed insight into the adsorption mechanism can be taken into account. For the MIP $_{\text {MAA }}$, the amount adsorbed of diuron on the two sites is very similar ( 7.21 and $8.41 \mathrm{mg} \mathrm{g}^{-1}$ ) and the difference between the parameters $\mathrm{K}_{1}$ and $\mathrm{K}_{2}$ are rather low ( 0.04 and $0.12 \mathrm{Lg}^{-1}$ ) compared to the other polymers. This finding makes possible to infer that binding sites ascribed to methacrylic acid distributed through polymeric network show similar affinity towards diuron adsorption, thus denoting an energetically homogeneous surface. Such result corroborates the adsorption kinetic described by pseudo first-order model and may explain the higher adsorption diuron onto MIP $\mathrm{MAA}$ compared to other polymers due to very low presence of non-selective binding sites in this polymer. On

Table 4

Selectivity parameters for the competitive adsorption (diuron/carbofuran/2,4-D) on the MIP $\mathrm{MA}_{\text {and NIP }}$ MA.

\begin{tabular}{|c|c|c|c|c|c|c|c|}
\hline \multirow[t]{2}{*}{ Polymers } & \multicolumn{3}{|l|}{$\mathrm{K}_{\mathrm{d}}\left(\mathrm{Lg}^{-1}\right)$} & \multicolumn{2}{|c|}{$\begin{array}{l}\mathrm{k}_{\mathrm{MIP}}=\frac{\mathrm{K}_{\mathrm{d}}(\text { diuron })}{\mathrm{K}_{\mathrm{d}}(\mathrm{CH})} \\
\mathrm{k}_{\mathrm{NIP}}=\frac{\mathrm{K}_{\mathrm{d}}(\text { diuron })}{\mathrm{K}_{\mathrm{d}}(\mathrm{CH})}\end{array}$} & \multicolumn{2}{|l|}{$\mathrm{k}^{\prime}=\frac{\mathrm{k}_{\mathrm{MIP}}}{\mathrm{k}_{\mathrm{NIP}}}$} \\
\hline & Diuron & Carbofuran & $2,4-D$ & Carbofuran & $2,4-D$ & Carbofuran & $2,4-\mathrm{D}$ \\
\hline MIP & 1332 & 123 & 83 & 11 & 16 & 3.0 & 5.5 \\
\hline NIP & 319 & 88 & 111 & 3.6 & 2.9 & & \\
\hline
\end{tabular}

Initial concentration of herbicides used in the assay was $10 \mathrm{mg} \mathrm{L}^{-1}$. 
the other hand, for the NIP ${ }_{\text {MAA }}$ a greater value between the $K_{1}$ $\left(0.02 \mathrm{~L} \mathrm{~g}^{-1}\right)$ and $\mathrm{K}_{2}\left(27.36 \mathrm{~L} \mathrm{~g}^{-1}\right)$ corresponds to a higher value between the $b_{1}\left(6.71 \mathrm{mg} \mathrm{g}^{-1}\right)$ and $b_{2}\left(0.53 \mathrm{mg} \mathrm{g}^{-1}\right)$, which indicates that more diuron was adsorbed on the lower-affinity sites $\left(b_{1}=\right.$ $6.71 \mathrm{mg} \mathrm{g}^{-1}$ and $\mathrm{K}_{1}=0.02 \mathrm{~L} \mathrm{~g}^{-1}$ ) onto the non-imprinted polymer. For the $\mathrm{MIP}_{\mathrm{AA}}$, as expected, the higher diuron adsorption $\left(7.07 \mathrm{mg} \mathrm{g}^{-1}\right.$ ) takes place on the higher-affinity sites, very likely on the selective binding sites. However, the $K_{2}$ value is rather low, demonstrating a low-energy character for these adsorption sites, which can explain the lower adsorption of diuron onto MIP $_{\mathrm{AA}}$ compared to MIP $\mathrm{MAA}$. As regards the $\mathrm{NIP}_{\mathrm{AA}}$, a similar behavior to the NIP $\mathrm{MAA}$ was observed, i.e., the adsorption of diuron occurs on the lower-affinity sites $\left(b_{1}=\right.$ $8.86 \mathrm{mg} \mathrm{g}^{-1}$ and $\mathrm{K}_{1}=4.4 \times 10^{-3} \mathrm{~L} \mathrm{~g}^{-1}$ ) owing to the absence of imprinting sites in this polymer.

\subsection{Selectivity for binding of diuron}

The selectivity of $\mathrm{MIP}_{\mathrm{MA}}$ and $\mathrm{MIP}_{\mathrm{AA}}$ towards adsorption of diuron was evaluated in the presence of two herbicides (carbofuran and 2,4D), which have very similar structure to diuron (Fig. 9). This study is a primary concern index to estimate MIP performance. Fig. 10 depicts the obtained $K_{d}$ values to the polymers, where it is possible to observe that the distribution constants of diuron on the MIP $\mathrm{MA}_{\mathrm{MA}}$ in a wide concentration range were much higher than the ones achieved for the MIP ${ }_{\mathrm{AA}}$, thereby demonstrating that acrylic acid monomer has, as already observed from kinetic and isotherm data, low affinity towards diuron. Additionally, under competitive adsorption, MIP $\mathrm{MA}$ was not able to satisfactory adsorb compounds with very similar structural molecule to diuron, being a strong indication of presence of selective binding site for the diuron. From the initial evaluation of rebinding diuron assays

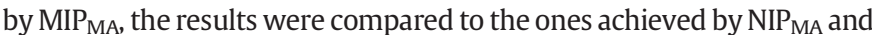
the selective coefficients $(k)$ and relative selectivity coefficient $\left(k^{\prime}\right)$ were determined as summarized in Table 4 . As can be seen, MIP had higher selective coefficients for the diuron/carbofuran and diuron/2,4-D systems than that for the NIP, thus giving rise to relative selectivity coefficient $\left(k^{\prime}\right)$ higher than one unit. Therefore, the selectivity of MIP was 3.0 and 5.5 times higher than NIP for the diuron/carbofuran and diuron/2,4D systems, which is very likely owing to the formation of more binding sites that match with diuron molecule in the molecularly imprinted polymer. Therefore, the MIP $\mathrm{MA}_{\mathrm{A}}$ had an excellent selectivity for diuron even in the presence of structurally similar molecules.

\section{Conclusion}

In this study we have synthesized diuron-molecule imprinted polymers using two types of monomers (methacrylic and acrylic acid). The use of methacrylic acid resulted in a polymer with higher surface area and higher adsorption capacity towards adsorption of diuron when compared to the one synthesized with acrylic acid. Also, it was found that the MIP ilar molecules, carbofuran and 2,4-D, when compared to NIP MAA. Therefore, the results demonstrate the feasibility in preparing phenylurea herbicide-selective materials using a very common monomer, inexpensive and available in routine laboratories, as well as makes possible to exploit the bulk polymerization, a very simple technique. For the final remarks, the combined use of non-linear kinetic and isotherm models can be a promising tool in obtaining more insight into the adsorption mechanism and existence of higher-affinity and lower-affinity adsorption sites for the studied polymers.

\section{Acknowledgments}

The authors would like to thank the Conselho Nacional de Desenvolvimento Científico e Tecnológico (CNPq) (Project Nos. 481669/2013-2, 305552/2013-9, 472670/2012-3), Coordenação de Aperfeiçoamento de Pessoal de Nivel Superior (CAPES), Fundação
Araucária do Paraná (163/2014), Fundação de Amparo a Pesquisa do Estado de São Paulo (FAPESP) (Project 2011/03008-7 and Instituto Nacional de Ciência e Tecnologia de Bioanalítica (INCT) (Project No. 573672/2008-3) for their financial support and fellowships.

\section{References}

[1] R.J. Fonseca, M.G. Segatelli, K.B. Borges, C.R.T. Tarley, Synthesis and evaluation of different adsorbents based on poly(methacrylic acid-trimethylolpropane trimethacrylate) and poly(vinylimidazole-trimethylolpropane trimethacrylate) for the adsorption of tebuthiuron from aqueous medium, React. Funct. Polym. 93 (2015) $1-9$.

[2] S. Giacomazzi, N. Cochet, Environmental impact of diuron transformation: a review, Chemosphere 56 (2004) 1021-1032.

[3] http://www.epa.gov/espp/litstatus/effects/diuron_analysis_final2.pdf. Accessed September 22, 2015.

[4] J.A. Field, R.L. Reed, T.E. Sawyer, M. Martinez, Diuron and its metabolites in surface water and ground water by solid phase extraction and in-vial elution, J. Agric. Food Chem. 45 (1997) 3897-3902.

[5] G.S.A. Fernandes, A.C. Arena, C.D.B. Fernandez, A. Mercadante, L.F. Barbisan, W.G. Kempinas, Reproductive effects in male rats exposed to diuron, Reprod. Toxicol. 23 (2007) 106-112.

[6] D.C. Gooddy, P.J. Chilton, I. Harrison, A field study to assess the degradation and transport of diuron and its metabolites in a calcareous soil, Sci. Total Environ. 297 (2002) 67-83.

[7] World Health Organization (WHO), Guidelines for Drinking-water Quality.Third Edition Incorporating the First and Second Addenda, vol. 12008 (http://www.who. int/water_sanitation_health/dwq/fulltext.pdf.Accessed September 22. 2015).

[8] European Commission. "Priority substances under the water framework directive" http://ec.europa.eu/environment/water/water-framework/priority_substances. htm. Accessed September 22, 2015.

[9] A. Wong, M.R.V. Lanza, M.D.P.T. Sotomayor, Sensor for diuron quantitation based on the P450 biomimetic catalyst nickel(II) 1.4.8.11.15.18.22.25-octabutoxy-29H.31Hphthalocyanine, J. Electroanal. Chem. 690 (2013) 83-88.

[10] M. Al Bhahri, L. Calvo, M.A. Gilarranz, J.J. Rodrigues, Activated carbon from grape seeds upon chemical activation with phosphoric acid: application to the adsorption of diuron from water, Chem. Eng. J. 203 (2012) 348-356.

[11] O. Bouras, J. Bollinger, M. Baudu, H. Khalaf, Adsorption of diuron and its degradation products from aqueous solution by surfactant-modified pillared clays, Appl. Clay Sci. 37 (2007) 240-250.

[12] G. Sheng, Y. Yang, M. Huang, K. Yang, Influence of pH on pesticide sorption by soil containing wheat residue-derived char, Environ. Pollut. 134 (2005) 457-463.

[13] Y.S. Al-Degs, A.H. El-Sheikh, S.T. Jaber, Application of heated date seeds as a novel extractant for diuron from water, Arab. J. Chem. 6 (6) (2013) 121-129.

[14] J. Deng, Y. Shao, N. Gao, Y. Deng, C. Tan, S. Zhou, X. Hu, Multiwalled carbon nanotubes as adsorbents for removal of herbicide diuron from aqueous solution, Chem. Eng. J. 193-194 (2012) 339-347.

[15] M. Streat, L.A. Sweetland, Removal of pesticides from water using hypercrosslinked polymer phases: part 2D sorption studies, Process. Saf. Environ. Prot. 76 (1998) 127-134.

[16] D.-L. Huang, R.-Z. Wang, Y.-G. Liu, G.-M. Zeng, C. Lai, P. Xu, B.-A. Lu, J.-J. Xu, C. Wong, C. Huang, Application of molecularly imprinted polymers in wastewater treatment: a review, Environ. Sci. Pollut. Res. 22 (2015) 963-977.

[17] C.R.T. Tarley, M.G. Segatelli, L.T. Kubota, Amperometric determination of chloroguaiacol at submicromolar levels after on-line preconcentration with molecularly imprinted polymers, Talanta 69 (2006) 259-266.

[18] G. Vasapollo, R.D. Sole, L. Mergola, M.R. Lazzo, A. Scardino, S. Scorrano, G. Mele, Molecularly imprinted polymers: present and future prospective, Int. J. Mol. Sci. 12 (2011) 5908-5945.

[19] Y. L-X, R. Fang, G.-H. Chen, Molecularly imprinted solid-phase extraction in the analysis of agrochemicals, J. Chromatogr. Sci. 51 (2013) 608-618.

[20] J. Wang, R. Guo, J. Chen, O. Zhang, X. Liang, Phenylurea herbicides-selective polymer prepared by molecular imprinting using $\mathrm{N}$-(4-isopropylphenyl)- $\mathrm{N}$-butyleneurea as dummy template, Anal. Chim. Acta 540 (2005) 307-315.

[21] R. Carabias-Martínez, E. Rodrígues-Gonzalo, E. Herreo-Hernández, M.E. Díaz-García, Development and characterisation of a molecularly imprinted polymer prepared by precipitation polymerization for the determination of phenylurea herbicides, J. Sep. Sci. 28 (2005) 453-461.

[22] F.G. Tamayo, J.L. Casillas, A. Martin-Esteban, Evaluation of new selective molecularly imprinted polymers prepared by precipitation polymerisation for the extraction of phenylurea herbicides, J. Chromatogr. A 1069 (2005) 173-181.

[23] P.A.G. Cormack, A.Z. Elorza, Molecularly imprinted polymers: synthesis and characterization, J. Chromatogr. B 804 (2004) 173-182.

[24] H. Yan, K.H. Row, Characteristic and synthetic approach of molecularly imprinted polymer, Int. J. Mol. Sci. 7 (2006) 155-178.

[25] C. Lourencetti, M.R.R. Marchi, M.L. Ribeiro, Determination of sugar cane herbicides in soil and soil treated with sugar cane vinasse by solid-phase extraction and HPLC-UV, Talanta 77 (2008) 701-709.

[26] M.M.C. Lopez, M.C.C. Perez, M.S.D. Garcia, J.M.L. Vilariño, M.V.G. Rodriguez, L.F.B. Losada, Anal. Chim. Acta 721 (2012) 68-78.

[27] A.C. Martins, O. Pexoti, A.L. Cazetta, K.C. Bedin, D.A.S. Yamazaki, G.F.G. Bandoch, T. Asefa, J.V. Visentainer, V.C. Almeida, Removal of tetracycline by $\mathrm{NaOH}$-activated carbon produced from macadamia nut shells: kinetic and equilibrium studies, Chem. Eng. J. 260 (2015) 291-299. 
[28] C.R.T. Tarley, M.Z. Corazza, B.F. Somera, M.G. Segatelli, Preparation of new ionselective cross-linked poly(vinylimidazole-co-ethylene glycol dimethacrylate) using a double-imprinting process for the preconcentration of $\mathrm{Pb}^{2+}$ ions, J. Colloid Interface Sci. 450 (2015) 254-263.

[29] T.O. Germiniano, M.Z. Corazza, M.G. Segatelli, E.S. Ribeiro, M.J.S. Yabe, E. Galunin, C.R.T. Tarley, Synthesis of novel copper ion-selective material based on hierarchically imprinted cross-linked poly(acrylamide-co-ethylene glycol dimethacrylate), React. Funct. Polym. 82 (2014) 72-80.

[30] I. Dakova, I. Karadiova, V. Georgieva, G. Georgiev, Synthesis and application of vinylpyridine containing ion-imprinted copolymer gel microbeads for $\mathrm{Cu}(\mathrm{II})$ solid-phase extraction, J. Sep. Sci. 35 (2012) 2805-2812.

[31] A. Corma, From microporous to mesoporous molecular sieve materials and their use in catalysis, Chem. Rev. 97 (1997) 2373-2419.

[32] F.M. de Oliveira, B.F. Somera, E.S. Ribeiro, M.G. Segatelli, M.J.S. Yabe, E. Galunin, C.R.T. Tarley, Kinetic and isotherm studies of $\mathrm{Ni}^{2+}$ sorption on poly(methacrylic acid) synthesized through a hierarchical double-imprinting method using a $\mathrm{Ni}^{2+}$ ion and cationic surfactant as templates, Ind. Eng. Chem. Res. 52 (2013) 8550-8557.

[33] M.A. Corazz, E.S. Ribeiro, M.G. Segatelli, C.R.T. Tarley, Study of cross-linked poly(methacrylic acid) and polyvinylimidazole as selective adsorbents for on-line preconcentration and redox speciation of chromium with flame atomic absorption spectrometry determination, Microchem. J. 117 (2014) 18-26.

[34] J. Lin, J. Lan, Comparison between linear and non-linear forms of pseudo first-order and pseudo-second-order adsorption kinetic models for the removal of methylene blue by activated carbon, Front. Environ. Sci. Eng. China 3 (2009) 320-324.
[35] Y.S. Ho, G. McKay, A comparison of chemisorption kinetic models applied to pollutant removal on various sorbents, Trans. I Chem. E 76B (1998) 332-340.

[36] K.Y. Foo, B.H. Hameed, Mesoporous activated carbon from wood sawdust by $\mathrm{K}_{2} \mathrm{CO}_{3}$ activation using microwave heating, Bioprocess Technol. 111 (2012) 425-432.

[37] Y. Xue, H. Hou, S. Zhu, Adsorption removal of reactive dyes from aqueous solution by modified basic oxygen furnace slag: isotherm and kinetic study, Chem. Eng. J. 147 (2009) 272-279.

[38] C. Zhou, O. Wu, T. Lei, I.I. Negulescu, Adsorption kinetic and equilibrium studies for methylene blue dye by partially hydrolyzed polyacrylamide/cellulose nanocrystal nanocomposite hydrogels, Chem. Eng. J. 251 (2014) 17-24.

[39] A.E. Ofomaja, Intraparticle diffusion process for lead(II) biosorption onto mansonia wood sawdust, Bioprocess Technol. 101 (2010) 5868-5876.

[40] W.H. Cheung, Y.S. Szeto, G. Mckay, Intraparticle diffusion processes during acid dye adsorption onto chitosan, Bioprocess Technol. 98 (2007) 2897-2904.

[41] I. Langmuir, The constitution and fundamental properties of solids and liquids, J. Am. Chem. Soc. 38 (1916) 2221-2295.

[42] H.M.F. Freundlich, Over the adsorption in solution, J. Phys. Chem. 57 (1906) 385-471.

[43] M.I. Tempkin, V. Pyzhev, Kinetics of ammonia synthesis on promoted iron catalyst, Acta Phys. Chim. USSR 12 (1940) 327-356.

[44] D.N. Clausen, I.M.R. Pires, C.R.T. Tarley, Improved selective cholesterol adsorption by molecularly imprinted poly(methacrylic acid)/silica $\left(\mathrm{PMAA}^{-\mathrm{SiO}_{2}}\right.$ ) hybrid material synthesized with different molar ratios, Mater. Sci. Eng. C 44 (2014) 99-108. 